\title{
SISTEMAS DE INDICADORES DE DESEMPENHO EM PROJETOS
}

\section{Julia Garaldi Borges}

Pós-graduanda pela ESSEC Business School

Engenheira de Produção da Escola Politécnica da Universidade de São Paulo - POLI/USP E-mail: julia.borges@ poli.usp.br (Brasil)

\section{Marly Monteiro de Carvalho}

Doutora em Engenharia de Produção pela Universidade Federal de Santa Catarina - UFSC Professora da Escola Politécnica da Universidade de São Paulo - POLI/USP E-mail: marlymc@usp.br (Brasil) 


\title{
SISTEMAS DE INDICADORES DE DESEMPENHO EM PROJETOS
}

\section{RESUMO}

O presente trabalho visa propor um sistema de indicadores de desempenho de projetos, a partir da análise da importância dos critérios de sucesso em projetos. A abordagem metodológica foi a de pesquisa-ação desenvolvida em uma empresa de engenharia, com atuação em diversos setores. Foram utilizadas várias fontes de evidência, tais como análise do atual sistema de indicadores da empresa, análise dos projetos nas bases de dados e entrevistas com os representantes do escritório e com os gerentes dos projetos. Os resultados da pesquisa apontam para a falta de ligação entre causa e efeito do sistema de indicadores da organização, bem como da falta de tratamento diferenciado para os diferentes tipos de projeto e de stakeholders da organização. O sistema de indicadores de desempenho proposto busca mitigar essas lacunas encontradas, cujo projeto piloto é flexível o suficiente para captar essas necessidades diferentes.

Palavras-chave: Projetos; Administração de Projetos; Avaliação de Desempenho; Sistemas de Indicadores de Desempenho.

\section{PERFORMANCE MANAGEMENT SYSTEMS IN PROJECTS}

\begin{abstract}
This study aims to propose a project performance indicators system, based on the analysis of the project success criteria's importance. The research took place in a company whose business includes engineering and infrastructure integrated solutions in various industrial sectors, based on action-research method. Multiple sources of evidence were used, such as analysis of the current system of indicators of the company, analysis of projects in the databases and interviews with representatives of the project office and project managers. The results show the lack of causal logic structure of the performance measure system and a lack customization according to the type of project and stakeholders. A new performance measure system was proposed to the studied organization, whose pilot project is flexible enough to cater to the contingency theory that differentiates indicators for each type of project and stakeholders.
\end{abstract}

Keywords: Project Management; Performance Appraisal (Project); Managerial Information System (Indicators; Project).

Revista de Gestão e Projetos - GeP, São Paulo, v. 2, n. 1, p 174-207, jan./jun. 2011. 


\section{INTRODUÇÃO}

Nas últimas décadas, o crescimento pelo interesse em sistemas de indicadores pode ser inferido pela compilação do número de publicações relacionadas ao assunto desde a década de 1980 até os anos 2000, feita por Neely (2005). Assim como, mais recentemente, a preocupação com esse tópico na área de projetos (Pillai et al., 2002; Crawford e Bryce, 2003; Kezner, 2006, 2011).

No entanto, trata-se de um tema ainda pouco tratado na literatura de projetos, com poucas abordagens que reflitam a importância de se adotar uma perspectiva de contingência, tanto com relação às necessidades dos tipos diferentes de projeto, quanto dos tipos diferentes de stakeholders.

O objetivo desse estudo é fazer uma análise crítica dos sistemas de indicadores adotados em empresas brasileiras e propor um sistema de indicadores de desempenho de projetos que seja flexível para considerar os aspectos contingenciais.

Esse artigo está estruturado em 6 seções: a 2, traz a síntese do quadro teórico; a 3, a metodologia de pesquisa adotada; a 4, a análise do sistema de indicadores de desempenho da empresa estudada; a 5, apresenta a proposição e a implementação piloto de um sistema contingencial de indicadores de desempenho; e a 6, finaliza o artigo com as conclusões e recomendações para trabalhos futuros.

\section{REVISÃO DA LITERATURA}

Segundo Barclay e Osei-Bryson (2010), medição de desempenho é a apuração e o monitoramento dos critérios de sucesso do projeto definidos pelos stakeholders representativos das dimensões de desempenho do projeto. Dessa forma, uma questão bastante importante é como definir um sistema para medição e acompanhamento desses critérios de sucesso por meio de indicadores de desempenho.

Para Kezner (2006), indicadores de desempenho, ou key performance indicators (KPIs), medem a qualidade do processo para alcançar os resultados finais, avaliados por meio de critérios de sucesso previamente definidos. Ademais, Kezner (2011) destaca que KPIs são métricas-chave para a avaliação desse sucesso, e detalha o significado de cada letra, como a seguir:

Revista de Gestão e Projetos - GeP, São Paulo, v. 2, n. 1, p 174-207, jan./jun. 2011. 
- Key (K) - principal contribuinte para o sucesso ou fracasso;

- Perfomance (P) - elementos mensuráveis, quantificáveis, ajustáveis e controláveis;

- Indicators (I) - representação razoável do desempenho presente e futuro.

Como os indicadores são um instrumento de avaliação do desempenho de um projeto, cujas medições devem ser comparadas com as metas previamente estabelecidas para tal projeto, não existe uma padronização dos mesmos, já que suas metas, ou mesmo da organização que o executa, não são absolutas para todos os empreendimentos. Apesar de não diferenciarem os tipos de indicadores abordados, diversos autores propuseram direcionamentos para a definição de sistemas de indicadores de desempenho para os projetos, bem como as características que eles devem apresentar.

Crawford e Bryce (2003) definem Sistema de Informação de Monitoramento e Avaliação de Projetos - SIMA (Project Monitoring and Evaluation Information System - MEIS) como um tipo de Sistema de Informação de Gerenciamento - SIG (Management Information Systems - MIS) desenvolvido para mitigar um desempenho de projeto insatisfatório, demonstrar comprometimento e promover o aprendizado organizacional para o benefício de projetos futuros. O SIMA, denominado 3D-Logframe, foi baseado no Logical Framework Approach (LFA), inicialmente utilizado pela Agência dos Estados Unidos para Desenvolvimento Internacional (United States Agency for International Development - USAID), visa facilitar as ações gerenciais de monitoramento e a avaliação além da fase de planejamento do projeto.

O modelo apresenta a forma de um prisma triangular e se baseia na lógica de que, para se atingir o nível superior, o nível inferior deve ser satisfeito. $\mathrm{Na}$ estrutura, esse modelo traz semelhanças com o "Prisma de Desempenho" apresentado por Neely et al. (2001), embora as faces sejam diferentes. Uma dimensão importante adicionada a esse modelo é a do tempo, por meio do acompanhamento das ações planejadas em relação às atividades realizadas. A variância pode ser verificada ao longo do tempo, planejado versus realizado, e ações podem ser tomadas com base nos resultados observados, conforme ilustra a Figura 1.

Revista de Gestão e Projetos - GeP, São Paulo, v. 2, n. 1, p 174-207, jan./jun. 2011. 
Figura 1 - Esquema representativo do modelo 3D-Logframe.

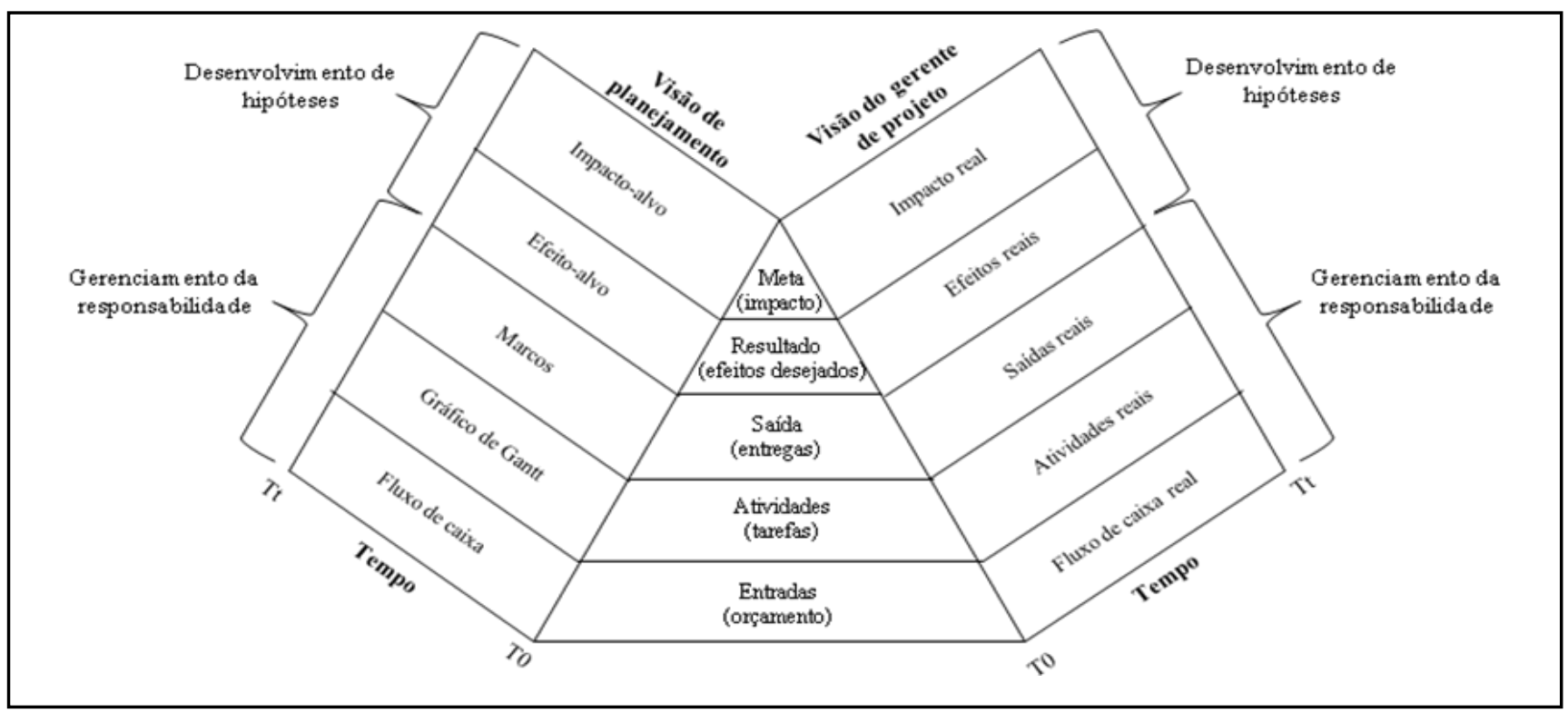

Legenda: $\mathrm{T} 0=$ tempo inicial $; \mathrm{Tt}=$ tempo em um instante $t$ Fonte: Crawford e Bryce, 2003.

A base do prisma triangular fornece as "regras do negócio" para a captura e a análise dos dados estabelecidos na lógica vertical. As regras do negócio são definidas para todas as camadas (Figura 2).

Figura 2 - Regras do negócio do modelo 3D-Logframe.

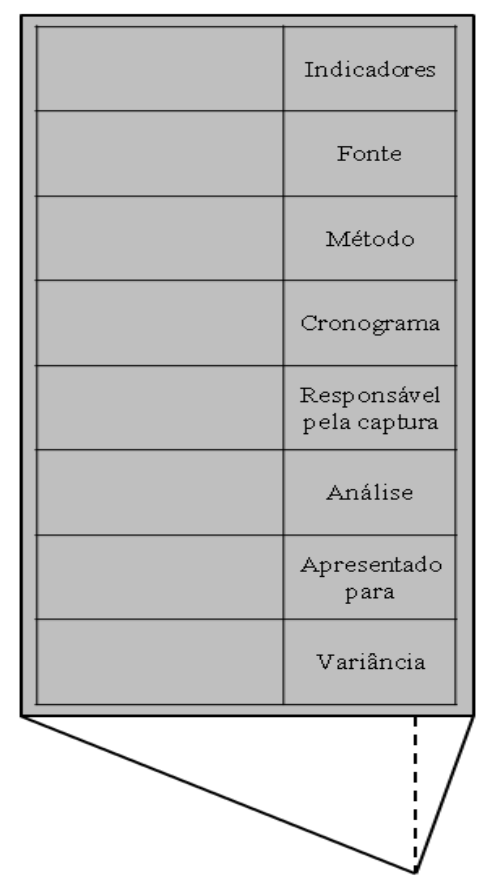

Fonte: Crawford e Bryce, 2003.

Revista de Gestão e Projetos - GeP, São Paulo, v. 2, n. 1, p 174-207, jan./jun. 2011. 
Outros autores sugerem a criação de índices de desempenho de projetos que visam avaliá-los de forma integrada. Pillai et al. (2002), ao analisarem projetos de pesquisa e desenvolvimento (P\&D), propõem a criação de um Índice de Desempenho Integrado (Integrated Performance Index) que englobe todo o ciclo de vida dos projetos de P\&D. O modelo identifica fatores chave para cada fase de seu ciclo de vida e os integra em uma fórmula para gerar tal índice, seguindo as seguintes etapas:

a) identificação das fases importantes do ciclo de vida;

b) identificação dos fatores chave de cada fase;

c) integração de todos os fatores identificados em um índice de desempenho integrado.

Para a compilação do indicador integrado, esses autores sugerem funções para o cálculo do desempenho do projeto sob alguns aspectos que irão compor tal índice, conforme Quadro 1.

\begin{tabular}{|c|c|}
\hline ASPECTO & DESCRIÇÃO \\
\hline Mérito & Representa o benefício esperado do projeto. \\
\hline Risco & $\begin{array}{l}\text { É a representação quantitativa da incerteza associada ao mérito } \\
\text { esperado do projeto. }\end{array}$ \\
\hline Categoria & $\begin{array}{l}\text { Refere-se à influência que o tipo de projeto exerce sobre seu } \\
\text { desempenho esperado. }\end{array}$ \\
\hline Status & $\begin{array}{l}\text { Para a determinação do status do projeto, os autores sugerem a } \\
\text { utilização de uma ferramenta gráfica, proposta por Pillai e Rao (1996), } \\
\text { que permite uma análise integrada de custo, progresso e tempo. }\end{array}$ \\
\hline Eficácia da decisão & $\begin{array}{l}\text { Representa a eficácia do atual sistema de gerenciamento de projetos no } \\
\text { sucesso da tomada de decisão. Esse fator pode ser medido pela } \\
\text { presença de processos julgados importantes para tomá-la. }\end{array}$ \\
\hline $\begin{array}{l}\text { Comprometimento do } \\
\text { cliente }\end{array}$ & Mede o nível de envolvimento do cliente com o projeto. \\
\hline Eficácia do custo & $\begin{array}{l}\text { Envolve questões como: custo do desenvolvimento; custo de } \\
\text { treinamento, de operação e de manutenção; etc. }\end{array}$ \\
\hline
\end{tabular}

Revista de Gestão e Projetos - GeP, São Paulo, v. 2, n. 1, p 174-207, jan./jun. 2011. 


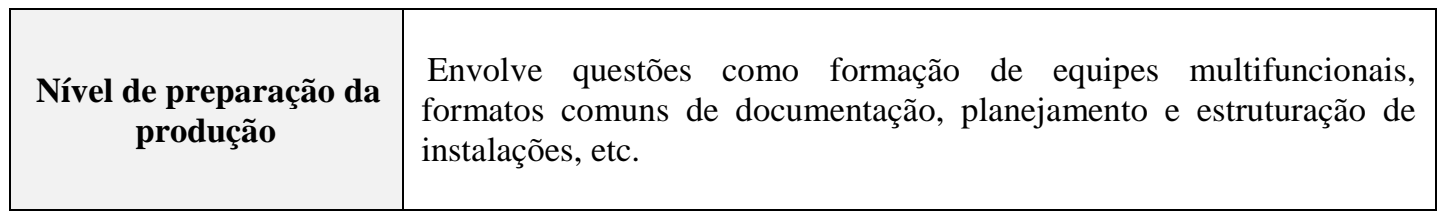

Quadro 1 - Aspectos considerados no índice de desempenho integrado.

Fonte: Adaptado de Pillai et al., 2002.

O índice integrado resultante é composto pelas variáveis normalizadas dos aspectos previamente apresentados, ponderados segundo os pesos definidos pelo patrocinador do projeto com base na sua perspectiva em relação à importância desses fatores. $\mathrm{O}$ índice resultante varia de 0 a 1.

Alguns autores destacam a importância de se criar um sistema de medição de desempenho cujas medidas sejam dinâmicas e acompanhem as questões consideradas relevantes para o negócio. Kennerley e Neely (2002) mencionam que as medidas devem evoluir depois da sua implementação, de modo a acompanhar as mudanças do próprio negócio. Assim, para desenvolver sistemas de indicadores é preciso analisar os geradores e direcionadores dessas mudanças e as barreiras que as impedem. Com base em uma análise detalhada dos fatores direcionadores e inibidores de mudanças, por meio de uma pesquisa realizada em sete empresas, esses autores sugerem que as seguintes questões inter-relacionadas devam ser levadas em consideração para se gerenciar efetivamente a evolução das medidas de desempenho:

- O uso ativo do sistema de medida de desempenho é um pré-requisito para qualquer evolução.

- O próprio sistema de medida de desempenho é composto por três elementos interrelacionados: medidas individuais, conjunto de medidas e a própria infraestrutura. Cada um desses elementos deve ser considerado durante a evolução do sistema.

- Existem quatro estágios de evolução: usar, refletir, modificar e implantar. Tais estágios formam um ciclo contínuo.

- Existirão barreiras que previnem a operação do ciclo evolucionário, as quais poderão ser ultrapassadas se o ciclo detiver direcionadores e impulsionadores, caracterizados nas macro categorias definidas pelos autores: processos, pessoas, infraestrutura e cultura. Tais categorias são descritas da seguinte forma:

Revista de Gestão e Projetos - GeP, São Paulo, v. 2, n. 1, p 174-207, jan./jun. 2011. 
processos - existência de processo de revisão, modificação e implantação de medidas;

* pessoas - disponibilidade das capacidades necessárias para usar, revisar, modificar e implantar as medidas;

* infraestrutura - disponibilidade de sistemas flexíveis que permitam a coleção, a análise e a disponibilização dos dados apropriados;

* cultura - a existência de uma cultura de medição dentro da organização deve garantir o valor e a manutenção das medidas apropriadas e relevantes.

Outro exemplo é a ferramenta proposta por Cheung et al. (2004). Visando atender às necessidades dos gerentes de projetos de manter seu projeto alinhado e monitorar restrições de prazo e orçamento, periodicamente, de modo a sinalizar possíveis ações necessárias, esses autores propõem um sistema de monitoramento baseado na internet Project Performance Monitoring System (PPMS). A proposta de tal sistema não se limita ao âmbito da empresa, uma vez que visa integrar diversas empresas da indústria de construção.

Como ponto de partida para a proposição da ferramenta, esses autores mencionam duas ferramentas de acompanhamento de indicadores de desempenho: uma desenvolvida pelo New South Wales Public Works Department, conhecida como Project Performance Evaluation (PPE) framework, e outra desenvolvida pelo KPI working group, dentro do UK Construction Industry Best Practice Programme, denominada Key Performance Indicators (KPIs), e para sua implementação definem os seguintes passos principais:

- Decisão sobre o que medir - é importante definir previamente quais serão as categorias de medidas de desempenho relevantes para a indústria de construção. As principais utilizadas no KPIs são: prazo, custo, qualidade, satisfação do cliente, mudanças dos clientes, desempenho do negócio, e segurança e saúde.

- Coleta dos dados - o processo é feito manualmente, a partir das informações fornecidas tanto pelo contratado, quanto pelo cliente.

- Cálculo dos indicadores de desempenho - é feito com base em formulações matemáticas previamente definidas. Calculam-se as médias da indústria disseminadas para os envolvidos, as quais são consideradas como benchmarks.

Revista de Gestão e Projetos - GeP, São Paulo, v. 2, n. 1, p 174-207, jan./jun. 2011. 
Cheung et al. (2004) reconhecem a validade das ferramentas mencionadas, mas apontam algumas limitações, tais como: o processo de coleta e a consolidação dos dados demanda muito tempo; clientes e contratados podem hesitar em fornecer informações ao coletor dos dados, por questões de confidencialidade; e há um tempo considerável para o processamento dos dados, de forma que a avaliação posterior fica comprometida. Visando lidar com as limitações apresentadas, propõe-se uma ferramenta baseada na internet, com a qual se relacionam os seguintes processos: entrada de dados (pelos próprios clientes e contratados), consolidação da base de dados, elaboração de relatórios e execução de ações corretivas.

Barclay e Osei-Bryson (2010) também propõem o desenvolvimento de uma estrutura de acompanhamento de desempenho de projetos, na qual seguem a seguinte metodologia:

- identificação dos stakeholders;

- estruturação dos objetivos baseada nas perspectivas dos stakeholders relevantes;

- priorização dos objetivos;

- identificação de medidas que possam ser usadas para medir os objetivos do projeto.

A ideia da elaboração de um sistema de medição de desempenho seguindo essas diretrizes evidencia a necessidade das organizações entenderem as condições sob as quais os projetos são desenvolvidos e de encontrarem medidas e indicadores adequados para a avaliação de seu desempenho.

Um exemplo de sistema que busca transformar informações qualitativas sobre os projetos em pontuações é a ferramenta conhecida como Project Health Indicator Tool (PHIT), desenvolvida pelo Construction Industry Institute (CII) (2006), em que um projeto é avaliado com base nas respostas a um questionário composto de 43 questões, que resultam em uma pontuação geral para o projeto como um todo e pontuações específicas para determinados critérios, os quais são atrelados aos resultados e às práticas de gerenciamento dos projetos previamente selecionados.

Novamente, observa-se que um sistema de indicadores de desempenho é particular a cada organização, que deve ser estruturado de forma a englobar os critérios de sucesso relevantes à mesma, e que estejam de acordo com a natureza de seus projetos e as perspectivas de seus stakeholders.

Revista de Gestão e Projetos - GeP, São Paulo, v. 2, n. 1, p 174-207, jan./jun. 2011. 


\section{METODOLOGIA}

Este trabalho busca propor um sistema de indicadores de desempenho de projetos, considerando a influência do tipo de projeto e de stakeholder, o qual foi desenvolvido em sete etapas, ilustradas na Figura 3 e detalhadas a seguir:

\section{a) Levantamento bibliográfico -}

- análise das tipologias propostas na literatura e verificação da sua aplicabilidade aos projetos da empresa estudada;

- análise da literatura de stakeholders para nortear os profissionais a serem consultados na pesquisa de campo;

- análise da literatura de sucesso de projetos e definição dos critérios de sucesso a serem analisados na pesquisa de campo;

- análise da literatura de sistemas de indicadores de desempenho para o direcionamento da etapa sete (proposição do sistema de indicadores).

b) Levantamento de dados - sobre os projetos desenvolvidos pela empresa estudada.

c) Análise de informações - sobre os projetos para a identificação de uma tipologia adequada aos projetos da empresa.

d) Pesquisa de campo - com diversos stakeholders que participaram de projetos de tipologias distintas, para avaliar o nível de importância de cada critério de sucesso definido com base na revisão bibliográfica.

e) Análise dos resultados da pesquisa de campo -

- validação das categorias de critérios sugeridas com base na pesquisa bibliográfica;

- análise da influência dos stakeholders e da tipologia do projeto no nível de importância dos critérios de sucesso analisados.

f) Análise crítica da ferramenta utilizada pela empresa - para o acompanhamento do sucesso de seus projetos.

Revista de Gestão e Projetos - GeP, São Paulo, v. 2, n. 1, p 174-207, jan./jun. 2011. 
g) Proposta de solução de um sistema de indicadores de desempenho - com base na fase de diagnóstico.

Figura 3 - Esquema resumo das etapas e metodologias aplicadas no presente trabalho.

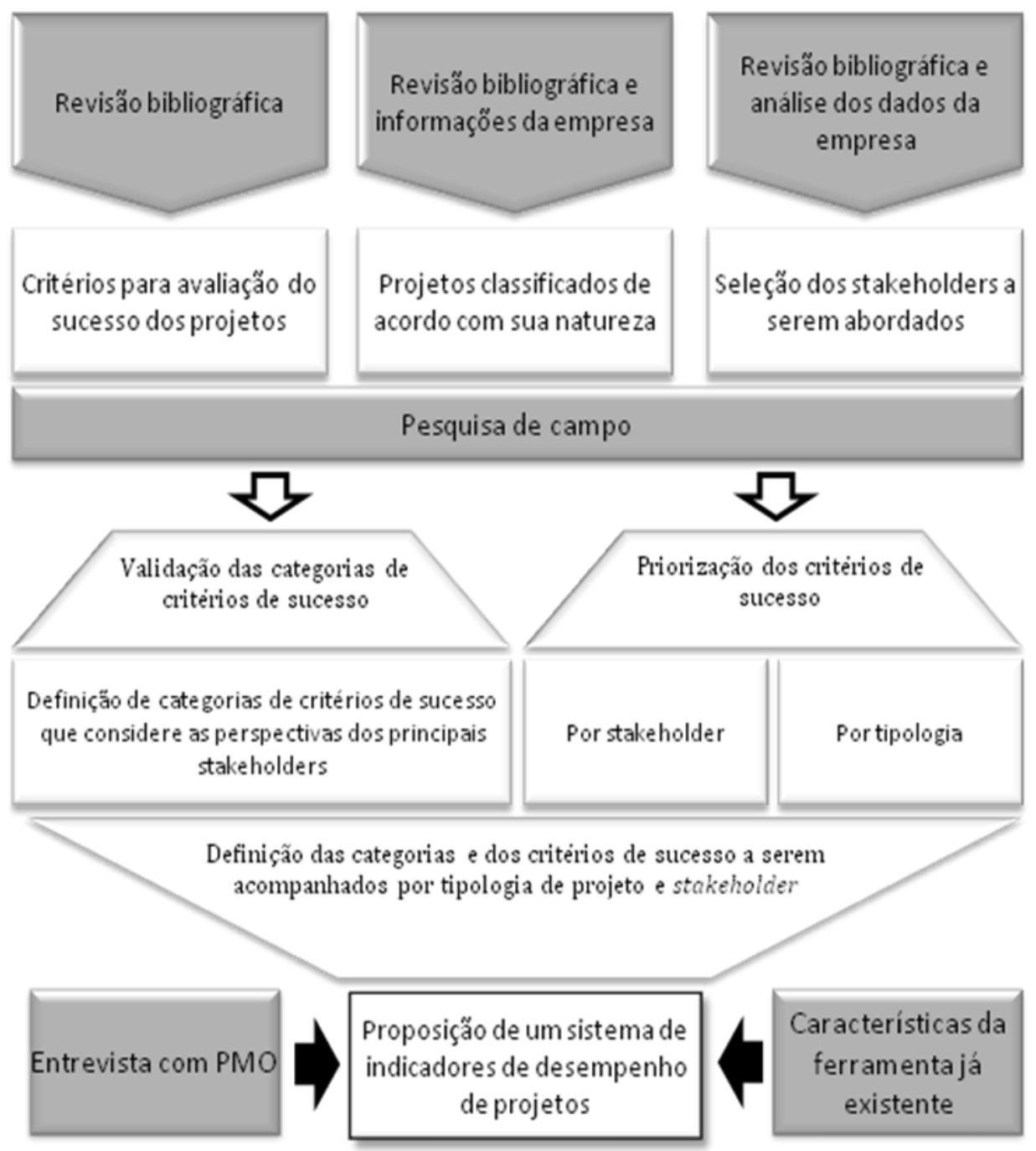

Legenda: PMO = Escritório de Gestão de Projetos.

A pesquisa utilizou vários tipos de evidências coletadas junto às bases de dados da empresa estudada, no ramo de engenharia (com atuação em diversos setores) bem como entrevistas com a equipe do Escritório de Gestão de Projetos (PMO) e um levantamento junto aos gerentes de projeto.

Para o levantamento das informações sobre os diversos projetos desenvolvidos pela organização, a partir de indicações dadas pelo responsável pelo PMO, foram consultadas planilhas de controle de projetos e o ERP (Enterprise Resources Planning) da empresa. Por não haver uma 
base de dados única e consolidada, um extenso levantamento de dados foi feito, com validação posterior pelo responsável pelo PMO.

Os dados obtidos nessa fase serviram de base para a definição das tipologias de projeto da empresa, bem como para o levantamento dos stakeholders envolvidos.

A partir do levantamento bibliográfico sobre sistemas de indicadores, foi possível identificar diversas variáveis que influenciam o processo de mensuração do desempenho, tais como a tipologia dos próprios projetos e as expectativas de seus stakeholders.

Portanto, antes de se prosseguir com o desenvolvimento do presente trabalho, fez-se necessária uma seleção das abordagens que o balizarão, com base no julgamento da sua adequação à natureza da pesquisa.

Com relação à tipologia de projetos adotada, a organização reconhece algumas variáveis para classificar aqueles que refletem a natureza do seu negócio, tais como tipo de produto, escopo do projeto, porte, entre outros aspectos que serão abordados com mais detalhes na seção de diagnóstico. Dessa forma, serão essas as dimensões consideradas para a análise da teoria contingencial mencionada por Shenhar (2001), no que se refere às tipologias de projetos.

Para a seleção dos stakeholders a serem abordados, será utilizada a grade de classificação e mapeamento proposto pelo Project Management Institute (PMI) (2008). Foram considerados apenas os stakeholders com alto interesse nos projetos e em seu sucesso.

Quanto à avaliação de sucesso, foram consideradas e adaptadas as categorias propostas por Shenhar e Dvir (2007), e dada sua multidimensionalidade e dinamicidade para contemplar critérios qualificadores, imprescindíveis para o desenvolvimento do projeto, foi adicionada uma nova dimensão de critérios denominada "critérios de conformidade".

Finalmente, o sistema de indicadores proposto baseou-se nas etapas sugeridas por Barclay e Osei-Bryson (2010), que apresentam a seguinte sequência:

- identificação dos stakeholders;

- estruturação dos objetivos baseada nas perspectivas dos stakeholders relevantes;

- priorização dos objetivos;

- identificação de medidas que podem ser usadas para medir os objetivos do projeto.

Consideraram-se as diretrizes apresentadas pelos diversos autores mencionados na revisão bibliográfica com foco nos aspectos mais amplamente destacados, como: necessidade de 
consideração dos principais stakeholders (Freeman, 1984); acompanhamento de tendências dos indicadores (Crawford e Bryce, 2003); flexibilidade para acompanhar a evolução dos indicadores, maximização da automatização e simplificação, e acompanhamento temporal (Kennerley e Neely, 2002). Também foi considerada a ideia de estruturação de uma plataforma baseada em rede proposta por Cheung et al. (2004). Finalmente, para a análise do ciclo de vida do sistema de indicadores foi utilizado o modelo proposto por Kennerley e Neely (2002).

\section{RESULTADOS DA PESQUISA}

Esta seção apresenta o diagnóstico da área de projetos da empresa, no que concerne à caracterização de seus projetos, dos principais stakeholders e do sistema de indicadores utilizado. Com base no diagnóstico e na análise crítica, propõe-se uma nova tipologia e novos critérios para a avaliação do sucesso dos projetos da empresa, os quais comporão um novo sistema de indicadores.

\subsection{ANÁLISE DO ATUAL SISTEMA DE INDICADORES DA EMPRESA}

O atual sistema de indicadores foi elaborado a partir da iniciativa do diretor executivo de uma das empresas do grupo. Em 2005 foi solicitada a apresentação de indicadores de desempenho que refletissem determinadas áreas de gerenciamento de projetos e algumas perspectivas estratégicas da empresa. Dentre os fatores que influenciaram essa solicitação incluíram-se:

- Identificação da ausência de padronização das medidas de desempenho dos processos de trabalho, bem como sua efetiva utilização pela empresa, lacuna destacada após a aplicação da avaliação de maturidade segundo o modelo OPM3 (Organizational Project Management Maturity Model, modelo para analisar a maturidade de uma organização em relação às suas práticas de gerenciamento de projetos) do PMI (2003) em suas unidades de negócio.

- Decisão de que a empresa concorreria ao Prêmio Nacional de Qualidade da Fundação Nacional da Qualidade (FNQ).

Revista de Gestão e Projetos - GeP, São Paulo, v. 2, n. 1, p 174-207, jan./jun. 2011. 
Dessa forma, um profissional do PMO dessa unidade de negócio - engenharia - elaborou uma planilha em MS Excel com o objetivo de viabilizar uma forma prática de avaliar os processos de trabalho dos projetos e do sistema de gerenciamento da empresa. Posteriormente, essa ferramenta foi compartilhada com as demais empresas do grupo, incluindo a organização foco do presente estudo. Desde então, a organização incluiu melhorias na ferramenta, com a finalidade de automatizar o processo de atualização dos dados e deixar suas informações de desempenho transparentes.

Quanto às principais barreiras enfrentadas na implantação da ferramenta, o responsável pelo PMO mencionou as seguintes questões:

- questionamento dos indicadores quanto à sua composição, aplicabilidade e comparabilidade;

- dificuldade de atendimento às expectativas dos diretores, principais clientes das informações, que tinham expectativa de uma ferramenta mais objetiva, que não dependesse de análises mais profundas de cada projeto;

- falta de apoio dos profissionais da alta gestão da empresa ao sistema de indicadores implantado, resultando em uma forte resistência dos responsáveis pelos projetos em utilizar as informações da ferramenta para seu gerenciamento.

Do ponto de vista do PMO, a ferramenta apresenta elevada utilidade, principalmente para a análise de desvios ocorridos ao longo do desenvolvimento dos projetos. Porém, a ferramenta ainda não recebeu ampla aceitação da direção geral da empresa.

O sistema de indicadores de desempenho em vigência na organização é composto de um conjunto de planilhas em MS Excel, quais sejam: uma consolidadora; uma para a inclusão de dados referentes aos diversos projetos; e várias individuais para cada projeto em desenvolvimento. Essas planilhas são atualizadas mensalmente, com o envolvimento dos profissionais responsáveis pelos projetos, além dos profissionais do PMO. O processo de atualização da ferramenta está apresentado na Figura 4.

Revista de Gestão e Projetos - GeP, São Paulo, v. 2, n. 1, p 174-207, jan./jun. 2011. 
Figura 4 - Fluxo do sistema de indicadores de desempenho de projetos da empresa.

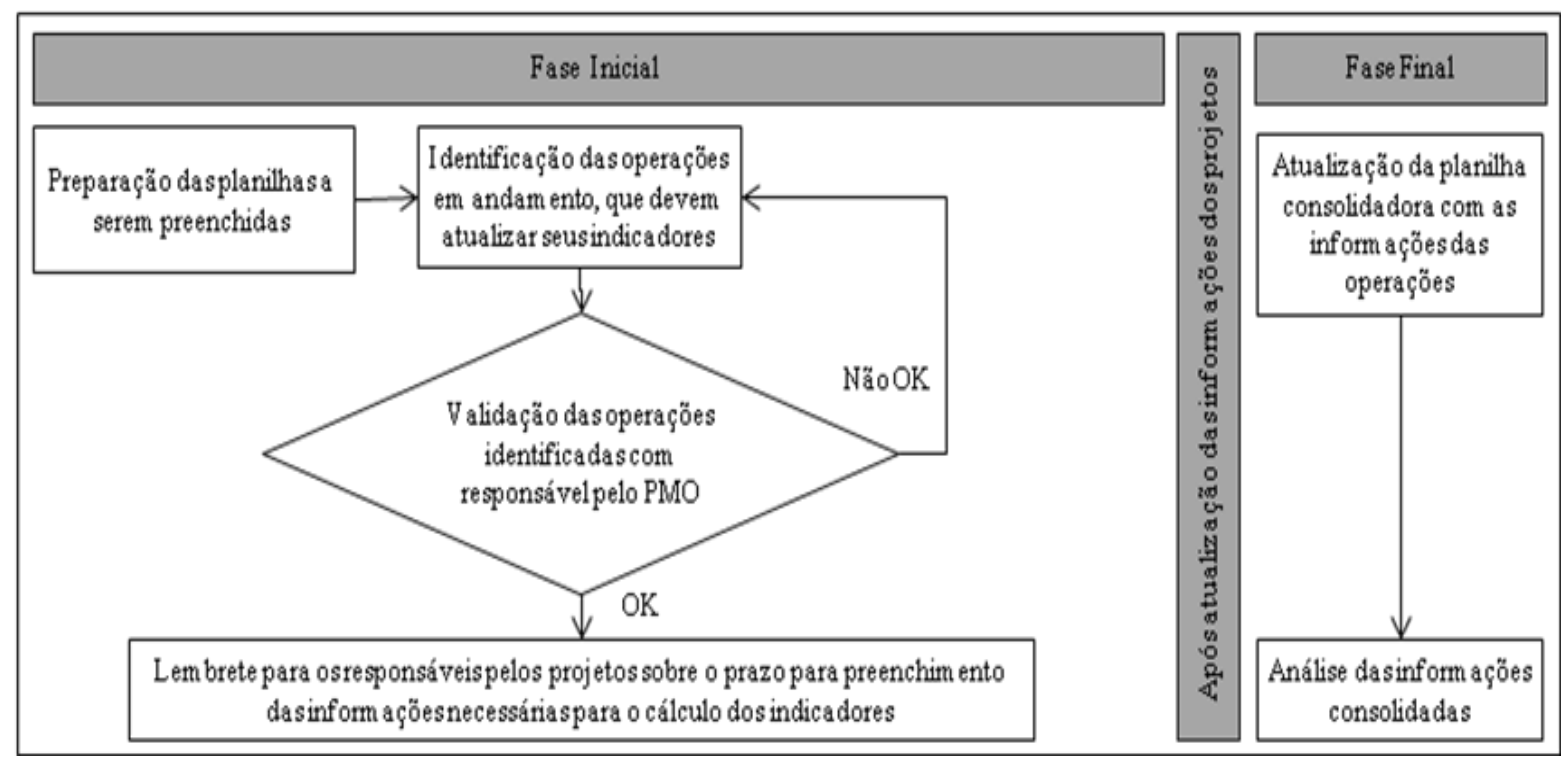

Como mostrado na Figura 4, o processo de atualização do sistema de indicadores é composto de três fases:

a) Fase inicial - um profissional do PMO prepara as planilhas que serão atualizadas no mês, sobre todos os projetos, faz alguns ajustes e inclui as informações já disponibilizadas por outros aplicativos. Após a compilação, com base nos critérios estabelecidos pela organização de obrigatoriedade de apresentação de informações de acordo com o andamento do projeto, a lista de projetos que deve alimentar o sistema no mês vigente é definida e validada. De acordo com essa lista, os responsáveis de cada projeto identificado são comunicados sobre a necessidade de apresentar suas informações e o prazo para essa atualização.

b) Fase sequenial - os responsáveis de cada projeto atualizam os dados de sua planilha, de forma a obter um resultado semafórico de todos os indicadores acompanhados pela empresa. Ou seja, os responsáveis dispõem da sinalização do indicador (verde, amarelo ou vermelho), de acordo com o valor do indicador e os limites pré-definidos para as sinalizações, mas não de seus valores numéricos. Esse conjunto de indicadores é apresentado em reuniões de acompanhamento do status do projeto, nas quais participam o gerente e os responsáveis pelo planejamento financeiro, além dos profissionais da alta direção da empresa. A visão final dos indicadores está apresentada na Figura 5.

Revista de Gestão e Projetos - GeP, São Paulo, v. 2, n. 1, p 174-207, jan./jun. 2011. 
Figura 5 - Visão final do status dos indicadores da empresa.

Detalhamento do Resultado do Painel de Bordo

\begin{tabular}{|c|c|c|c|c|c|c|c|c|c|c|c|}
\hline 1 & 2 & 3 & 4 & 5 & $6 \mathrm{~A}$ & $6 \mathrm{~B}$ & $7 \mathrm{~A}$ & $7 \mathrm{~B}$ & 8 & 9 & 10 \\
\hline 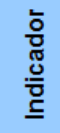 & 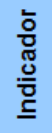 & 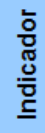 & 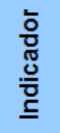 & 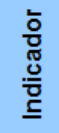 & 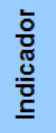 & 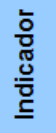 & 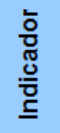 & 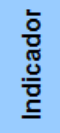 & 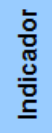 & 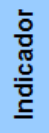 & 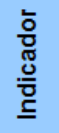 \\
\hline (2) & (2) & & & & (2) & (2) & (ㄱ) & (i) & & (i) & (2) \\
\hline 11 & 12 & 13 & $14 \mathrm{~A}$ & $14 \mathrm{~B}$ & 15 & $16 \mathrm{~A}$ & $16 \mathrm{~B}$ & $16 \mathrm{C}$ & $16 D$ & 17 & 18 \\
\hline 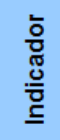 & 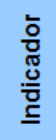 & 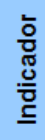 & 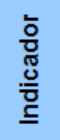 & 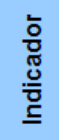 & 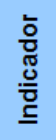 & 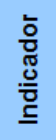 & 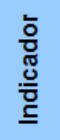 & 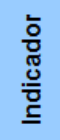 & 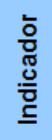 & 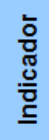 & $\begin{array}{l}\frac{5}{0} \\
\frac{\pi}{0} \\
\frac{\pi}{0}\end{array}$ \\
\hline (i) & (i) & (): & (2) & & & & & & & & \\
\hline
\end{tabular}

Fonte: Adaptada do material da organização.

c) Fase final - após a atualização das informações referentes a cada projeto, por meio de uma planilha consolidadora, um profissional do PMO agrupa todas essas informações e elabora gráficos e relatórios com os indicadores de desempenho dos projetos resultantes, os quais serão analisados e acompanhados pelo PMO da empresa.

As informações do sistema de indicadores da organização fornecem uma visão geral dos aspectos de eficiência e a eficácia dos projetos, tomando-se como base de comparação as metas estabelecidas anualmente pela alta direção e pelos profissionais do PMO. A ferramenta identifica as áreas de conhecimento que apresentam indicadores com resultados deficitários em relação às metas previamente estabelecidas, o que permite, a partir dessa análise, programar análises críticas e verificar as causas raiz para os desvios.

Revista de Gestão e Projetos - GeP, São Paulo, v. 2, n. 1, p 174-207, jan./jun. 2011. 


\subsubsection{ANÁLISE CRÍTICA DA FERRAMENTA UTILIZADA NA EMPRESA}

Com base nos indicadores acompanhados no sistema da empresa, buscou-se identificar o peso de cada critério de sucesso para a avaliação de seus projetos.

A ferramenta agrupa seus indicadores de acordo com as seguintes perspectivas: cliente, fornecedores, conhecimento, financeira e processos. Para cada uma dessas áreas são definidos um ou mais indicadores para a avaliação do projeto segundo determinados critérios. Para cada um desses indicadores são definidas faixas de avaliação para determinar se o indicador apresenta um valor "insatisfatório" (vermelho), "requer atenção" (amarelo) ou "satisfatório" (verde). Ao final da compilação do status de cada indicador é calculado um índice geral do projeto, obtido por meio da razão entre o número de indicadores com status satisfatório sobre o número total de indicadores compilados.

Buscando analisar o grau de importância dos critérios de sucesso considerados pela empresa, procurou-se relacionar os indicadores por ela acompanhados com os critérios de sucesso levantados a partir da pesquisa bibliográfica e validados por meio da pesquisa de campo. A Tabela 1 agrupa os indicadores analisados de acordo com os critérios de sucesso estudados, relacionando a quantidade de indicadores identificados para cada critério.

Tabela 1 - Indicadores acompanhados na empresa por critério de sucesso.

\begin{tabular}{|c|c|c|c|}
\hline $\begin{array}{l}\text { CATEGORIAS } \\
\text { DE CRITÉRIOS }\end{array}$ & CRITÉRIOS DE SUCESSO & INDICADOR DA EMPRESA & $\begin{array}{l}\text { NÚMERO DE } \\
\text { INDICADORES }\end{array}$ \\
\hline \multirow{4}{*}{ Eficiência } & $\begin{array}{l}\text { Cumprimento do orçamento } \\
\text { (custo) }\end{array}$ & $\begin{array}{l}\text { Desvios de custo em relação ao } \\
\text { baseline }\end{array}$ & 1 \\
\hline & Capacidade dos fornecedores & $\begin{array}{c}\text { Desempenho dos fornecedores e } \\
\text { variação no custo das contratações } \\
\text { previstas }\end{array}$ & 1 \\
\hline & Nível de risco & $\begin{array}{l}\text { Contingência transferida para } \\
\text { margem, contingência transferida } \\
\text { para custo, análise de impactos não } \\
\text { previstos, e comparação da } \\
\text { contingência em relação à receita }\end{array}$ & 4 \\
\hline & Presença de desvios & $\begin{array}{l}\text { Desvios de horas previstas (em } \\
\text { comparação com o baseline e com } \\
\text { os } 3 \text { últimos meses incorridos), } \\
\text { desvios de quantitativos, e desvios } \\
\text { de custo por mudança de escopo }\end{array}$ & 4 \\
\hline
\end{tabular}

Revista de Gestão e Projetos - GeP, São Paulo, v. 2, n. 1, p 174-207, jan./jun. 2011. 


\begin{tabular}{|c|c|c|c|}
\hline $\begin{array}{l}\text { CATEGORIAS } \\
\text { DE CRITÉRIOS }\end{array}$ & CRITÉRIOS DE SUCESSO & INDICADOR DA EMPRESA & $\begin{array}{l}\text { NÚMERO DE } \\
\text { INDICADORES }\end{array}$ \\
\hline \multirow{5}{*}{$\begin{array}{c}\text { Nível de } \\
\text { satisfação }\end{array}$} & $\begin{array}{c}\mathrm{A} \\
\text { lta satisfação ou moral da } \\
\text { equipe }\end{array}$ & na & 0 \\
\hline & Benefícios para o cliente & na & 0 \\
\hline & $\begin{array}{c}\text { Retenção dos membros da } \\
\text { equipe }\end{array}$ & na & 0 \\
\hline & Ausência de conflitos & na & 0 \\
\hline & Satisfação do gerente do projeto & na & 0 \\
\hline \multirow{5}{*}{$\begin{array}{l}\text { Impacto para os } \\
\text { negócios }\end{array}$} & Medidas econômicas & $\begin{array}{l}\text { Previsibilidade da margem de } \\
\text { contribuição absoluta e percentual }\end{array}$ & 2 \\
\hline & Tecnologia nova & na & 0 \\
\hline & Mercado novo & na & 0 \\
\hline & Nova competência essencial & na & 0 \\
\hline & Nova capacidade organizacional & na & 0 \\
\hline \multirow{4}{*}{$\begin{array}{c}\text { Impacto para o } \\
\text { cliente }\end{array}$} & Cumprimento de requisitos & $\begin{array}{c}\text { Multas contratuais por } \\
\text { descumprimento de escopo e } \\
\text { porcentagem de aceitação dos } \\
\text { deliverables entregues } \\
\end{array}$ & 2 \\
\hline & Fluxo de caixa & Saldo de caixa do projeto & 1 \\
\hline & Satisfação e lealdade do cliente & Satisfação do cliente & 1 \\
\hline & Reconhecimento da marca & na & 0 \\
\hline \multirow{2}{*}{$\begin{array}{l}\text { Critérios de } \\
\text { conformidade }\end{array}$} & Respeito ao meio ambiente & $\begin{array}{c}\text { Quantidade de notificações } \\
\text { ambientais }\end{array}$ & 1 \\
\hline & Respeito à sociedade & na & 0 \\
\hline
\end{tabular}

Revista de Gestão e Projetos - GeP, São Paulo, v. 2, n. 1, p 174-207, jan./jun. 2011. 


\begin{tabular}{|c|c|c|c|}
\hline $\begin{array}{c}\text { CATEGORIAS } \\
\text { DE CRITÉRIOS }\end{array}$ & CRITÉRIOS DE SUCESSO & INDICADOR DA EMPRESA & $\begin{array}{c}\text { NÚMERO DE } \\
\text { INDICADORES }\end{array}$ \\
\hline & $\begin{array}{c}\text { Conformidade com normas e } \\
\text { legislação }\end{array}$ & na & 0 \\
\cline { 2 - 4 } & Segurança & Taxa de frequência sem afastamento & 1 \\
\cline { 2 - 4 } & $\begin{array}{c}\text { Atendimento às metas } \\
\text { estratégicas }\end{array}$ & na & 0 \\
\hline Cumprimento de cronograma (prazo) & $\begin{array}{c}\text { Desvios de prazo e penalidades de } \\
\text { prazo }\end{array}$ & 2 \\
\hline Clareza na comunicação & $\begin{array}{c}\text { Presença das pessoas chave nos } \\
\text { eventos de controle dos projetos }\end{array}$ & 1 \\
\hline
\end{tabular}

Legenda: na = não se aplica.

Observando-se a Tabela 1 nota-se que os critérios de sucesso com maior nível de importância no sistema de indicadores da empresa são "presença de desvios" e "nível de risco". Em seguida, destacam-se os critérios "cumprimento de cronograma", "medidas econômicas" e "cumprimento de requisitos e especificações". Catorze critérios não são contemplados no atual sistema de indicadores da empresa.

A distribuição dos indicadores presentes na ferramenta e na sua correspondência com os critérios de sucesso estudados na literatura está apresentada na Figura 6. 
Figura 6 - Distribuição dos indicadores e critérios por categoria.

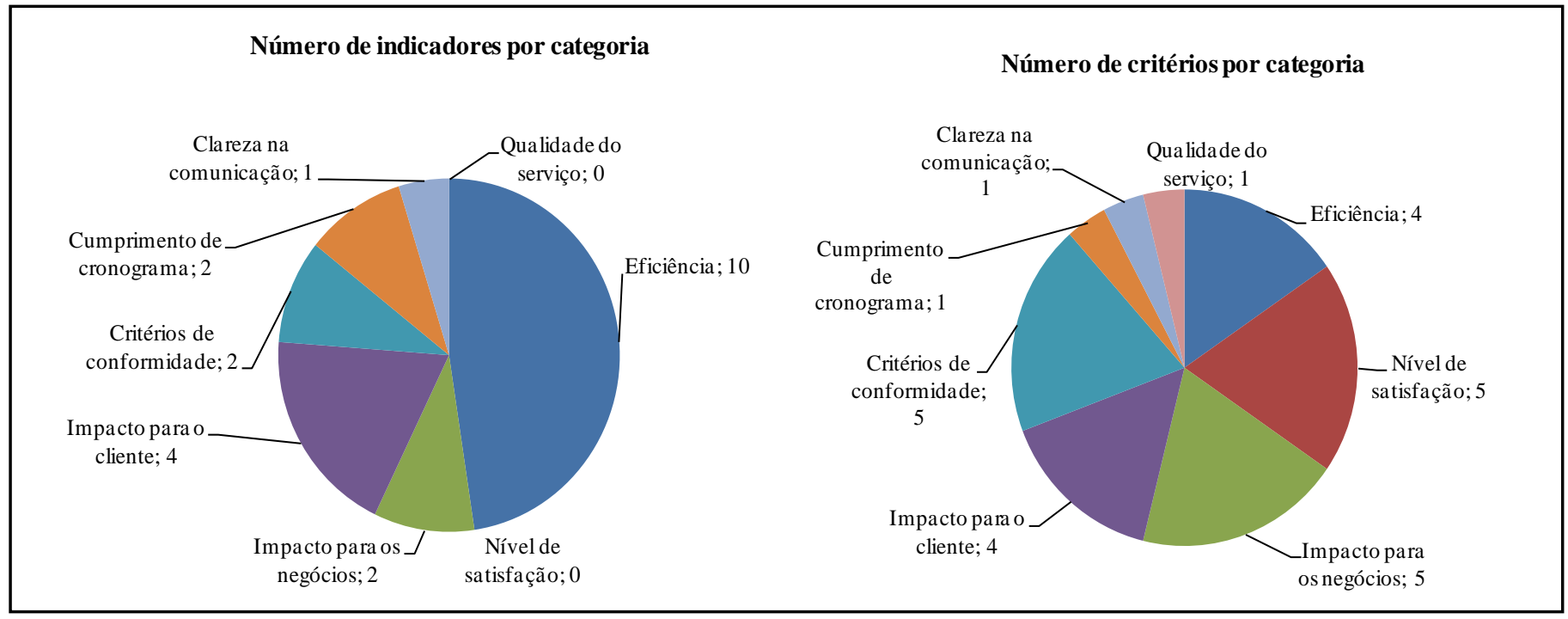

Observa-se que, com exceção da categoria "impacto para o cliente" e o critério "clareza na comunicação", há uma discrepância evidente entre o número de indicadores de desempenho da empresa relativos a cada categoria de critério e o número de critérios para cada categoria, resultante da pesquisa de campo e da literatura. Não há, por exemplo, indicadores que contemplem a categoria "nível de satisfação" e o critério "qualidade do serviço". Assim, pode-se concluir que existe certo desbalanceamento na atual ferramenta, que deve ser contornado de maneira a contemplar todos os critérios de sucesso das categorias definidas a partir da pesquisa de campo e da bibliografia, segundo as perspectivas dos stakeholders consultados.

\subsection{PROPOSIÇÃO DE UM NOVO SISTEMA DE INDICADORES DE DESEMPENHO}

Uma vez que a empresa já dispunha de uma ferramenta de acompanhamento de desempenho de projetos, ela foi utilizada como base para o novo sistema, o qual foi elaborado a partir da identificação de suas limitações e recebeu sugestão de propostas para sua melhoria.

Os feedbacks dos profissionais envolvidos na atualização do sistema atual, a opinião do responsável pelo PMO apresentada durante a entrevista, e os aspectos levantados na pesquisa bibliográfica, permitiram a sugestão dos seguintes pontos de melhoria:

Revista de Gestão e Projetos - GeP, São Paulo, v. 2, n. 1, p 174-207, jan./jun. 2011. 
- Como muitos dados são inseridos manualmente e não automaticamente, eles estão sujeitos às manipulações indesejáveis que comprometem sua validade e acarretam elevado tempo de atualização das informações.

- Não há apresentação dos valores numéricos dos indicadores, apenas o semafórico indicativo de resultado "satisfatório" (verde), "requer atenção" (amarelo) e "insatisfatório" (vermelho), definidos com base em critérios estabelecidos pelo PMO, o que dificulta a real avaliação do desempenho do projeto.

- Não há apresentação do histórico dos valores dos indicadores de maneira a evidenciar as tendências do desempenho do projeto em determinadas áreas, nem seu histórico é guardado para propiciar o aprendizado organizacional.

- Como observado na etapa de diagnóstico, os indicadores da ferramenta atualmente utilizada na empresa não contemplam as perspectivas de seus principais stakeholders, já que ignora critérios de sucesso considerados relevantes e define níveis de importância para categorias de critérios discrepantes com suas expectativas.

$\mathrm{Na}$ seção seguinte é proposto um sistema de indicadores de desempenho baseado nas limitações levantadas anteriormente e na literatura concernente ao assunto.

\subsection{PROJETO PILOTO}

No decorrer de desenvolvimento do presente trabalho a empresa iniciou um projeto piloto, com o envolvimento dos pesquisadores, com o objetivo de implantar um sistema de indicadores gerenciais diretamente ligado ao ERP da organização, com atualização automática e visualização online. Inicialmente, esse projeto foi planejado para incorporar indicadores de caráter mais estratégico. Porém, dada a análise crítica do sistema atual, decidiu-se pela inclusão dos indicadores de desempenho de projetos nessa mesma plataforma. Dessa forma, o novo sistema de indicadores de desempenho proposto toma como base a plataforma utilizada no projeto piloto em desenvolvimento na empresa.

Revista de Gestão e Projetos - GeP, São Paulo, v. 2, n. 1, p 174-207, jan./jun. 2011. 
A estrutura da ferramenta em implantação está diretamente incorporada ao ERP da empresa e permite a integração com outros sistemas de informação, de bancos de dados mais complexos às planilhas em MS Excel. A Figura 7 apresenta um esquema explicativo da arquitetura da plataforma para o desenvolvimento do sistema de indicadores de desempenho.

Figura 7 - Estruturação da plataforma para o desenvolvimento do sistema de indicadores de desempenho.

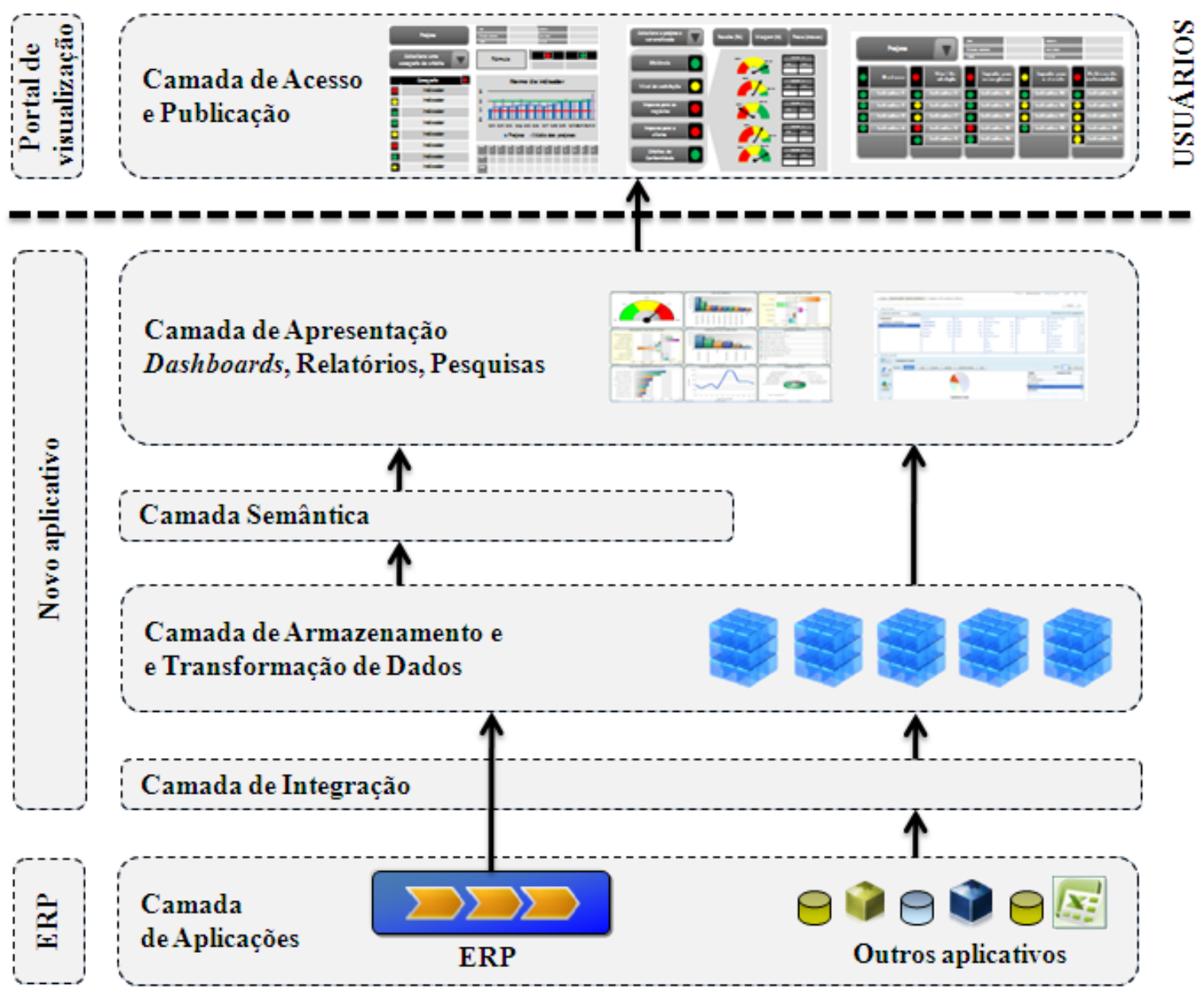

Fonte: Adaptada do material da organização.

Revista de Gestão e Projetos - GeP, São Paulo, v. 2, n. 1, p 174-207, jan./jun. 2011. 
Como apresentado no esquema da Figura 7, o sistema é formado por diversas camadas:

- Camada de aplicações - composta pelo ERP da empresa e pelos diversos aplicativos (bancos de dados, planilhas, etc.) que fornecem os dados à ferramenta.

- Camada de integração - destinada à integração dos dados não provenientes do ERP da empresa.

- Camada de armazenamento e transformação de dados - destinada à consolidação das informações provenientes dos diversos aplicativos fornecedores de dados.

- Camada semântica - destinada ao estabelecimento de uma terminologia padrão a ser utilizada na busca das informações, de maneira a permitir a fácil navegação na interface final.

- Camada de apresentação - composta dos indicadores calculados a partir dos dados armazenados, estruturados em painéis de controle customizados para as necessidades da organização.

- Camada de acesso e publicação - acessível aos usuários finais, consiste em um portal que pode ser acessado pela web, composto de máscaras customizadas com os indicadores selecionados pela organização.

\subsection{CARACTERÍSTICAS DO SISTEMA DE INDICADORES PROPOSTO}

O sistema de indicadores de desempenho de projeto proposto se baseou nas etapas sugeridas por Barclay e Osei-Bryson (2010). No presente trabalho, somente as três primeiras foram contempladas. Primeiramente, identificou-se os principais stakeholders e, posteriormente, por meio de um questionário, obteve-se suas perspectivas quanto à priorização dos critérios de sucesso dos projetos. Não obstante, o resultado da análise das perspectivas dos stakeholders não demonstrou diferenças significativas nas perspectivas dos profissionais consultados quanto ao nível de importância para a maioria dos critérios analisados. Consequentemente, para a empresa estudada, não há necessidade de diferenciação por tipo de stakeholder interno do projeto. Porém, no estudo elaborado, também foi incluída a análise da diferenciação do nível de importância desses critérios em relação à tipologia do projeto. Nesse caso, verificou-se uma diferença significativa entre os tipos de projetos, a qual deverá ser contemplada no sistema de indicadores proposto.

Revista de Gestão e Projetos - GeP, São Paulo, v. 2, n. 1, p 174-207, jan./jun. 2011. 
Com relação à última etapa, definição das medidas propriamente ditas, apesar de não compor o escopo do presente trabalho, sugere-se o seu embasamento nas "regras do negócio" definidas no modelo 3D-Logframe, apresentado por Crawford e Bryce (2003), no qual se incluem as seguintes definições para cada indicador: sua fonte, seu método de medição, seu cronograma da medição, o responsável pela captura de informações e o intervalo de variância do indicador.

Uma vez definidos esses aspectos, a proposta de sistema buscou considerar algumas características fundamentais que devem ser apresentadas por sistemas de indicadores eficazes, segundo a literatura. O Quadro 2 resume os aspectos enfocados e os autores que os mencionaram.

\begin{tabular}{|l|c|}
\hline \multicolumn{1}{|c|}{\begin{tabular}{|c|}
\multicolumn{1}{|c|}{ ASPECTO DO SISTEMA DE INDICADORES DE } \\
DESEMPENHO
\end{tabular}} & AUTORES \\
\hline $\begin{array}{l}\text { Simplicidade na coleta de dados/Automatização } \\
\text { Acompanhamento consistente ao longo do tempo, com foco em análise } \\
\text { de tendências e registro de histórico }\end{array}$ & Crawford e Bryce (2003) \\
\hline $\begin{array}{l}\text { Consideração das perspectivas dos principais stakeholders } \\
\text { Flexibilidade para contemplar a evolução dos indicadores }\end{array}$ & Freman (1984) \\
\hline
\end{tabular}

Quadro 2 - Aspectos fundamentais do sistema de indicadores de desempenho.

O sistema proposto considera como pressuposto a utilização da plataforma em desenvolvimento na empresa descrita na seção anterior. Essa ferramenta apresenta certa semelhança àquela proposta por Cheung et al. (2004), já que utiliza o conceito de rede para a integração dos profissionais que fazem uso das informações do aplicativo.

Tal sistema pode ser divido em dois componentes: configuração e visualização. Na parte da configuração são feitas as definições que determinam a visualização do sistema. O Quadro 3 apresenta as definições necessárias na fase da configuração e as referências de máscaras sugeridas para essa configuração.

Revista de Gestão e Projetos - GeP, São Paulo, v. 2, n. 1, p 174-207, jan./jun. 2011. 


\begin{tabular}{|c|c|}
\hline CONFIGURAÇÕES & $\begin{array}{c}\text { MÁSCARA } \\
\text { REFERENTE }\end{array}$ \\
\hline Classificação de cada projeto de acordo com seu tipo & Figura 8 \\
\hline Definição das categorias de critérios de sucesso consideradas & \multirow{4}{*}{ Figura 9} \\
\hline Definição dos critérios de sucesso que compõe cada categoria & \\
\hline Definição dos indicadores para avaliação de cada critério definido & \\
\hline Definição do nível de importância de cada critério de acordo com o tipo de projeto & \\
\hline Consolidação do peso dos critérios de sucesso para cada tipo de projeto & Figura 10 \\
\hline Definição dos critérios do semafórico & Figura 11 \\
\hline Detalhamento de cada indicador & Figura 12 \\
\hline
\end{tabular}

Quadro 3 - Configurações necessárias e máscaras sugeridas.

Uma vez identificada a diferenciação no nível de importância dos critérios de sucesso de acordo com sua tipologia, faz-se necessária a classificação inicial dos projetos de acordo com os tipos previamente estabelecidos. Dessa forma, para cada um deve-se apresentar uma descrição sucinta e a seleção do seu tipo, de acordo com suas características.

Outra configuração necessária refere-se aos critérios de sucesso considerados, seu agrupamento, seus indicadores e seu nível de importância para cada tipo de projeto. A Figura 8 apresenta uma máscara que visa definir essa configuração com um exemplo para a categoria de critérios denominada "critérios de conformidade", em que são apresentados todos os critérios de sucesso de projetos considerados importantes para a empresa, bem como a categoria à qual eles foram agrupados, os indicadores utilizados para sua medida e o nível de importância desse indicador e critério para cada tipo.

Figura 8 - Definição dos pesos dos critérios de sucesso para cada tipo de projeto.

Revista de Gestão e Projetos - GeP, São Paulo, v. 2, n. 1, p 174-207, jan./jun. 2011. 


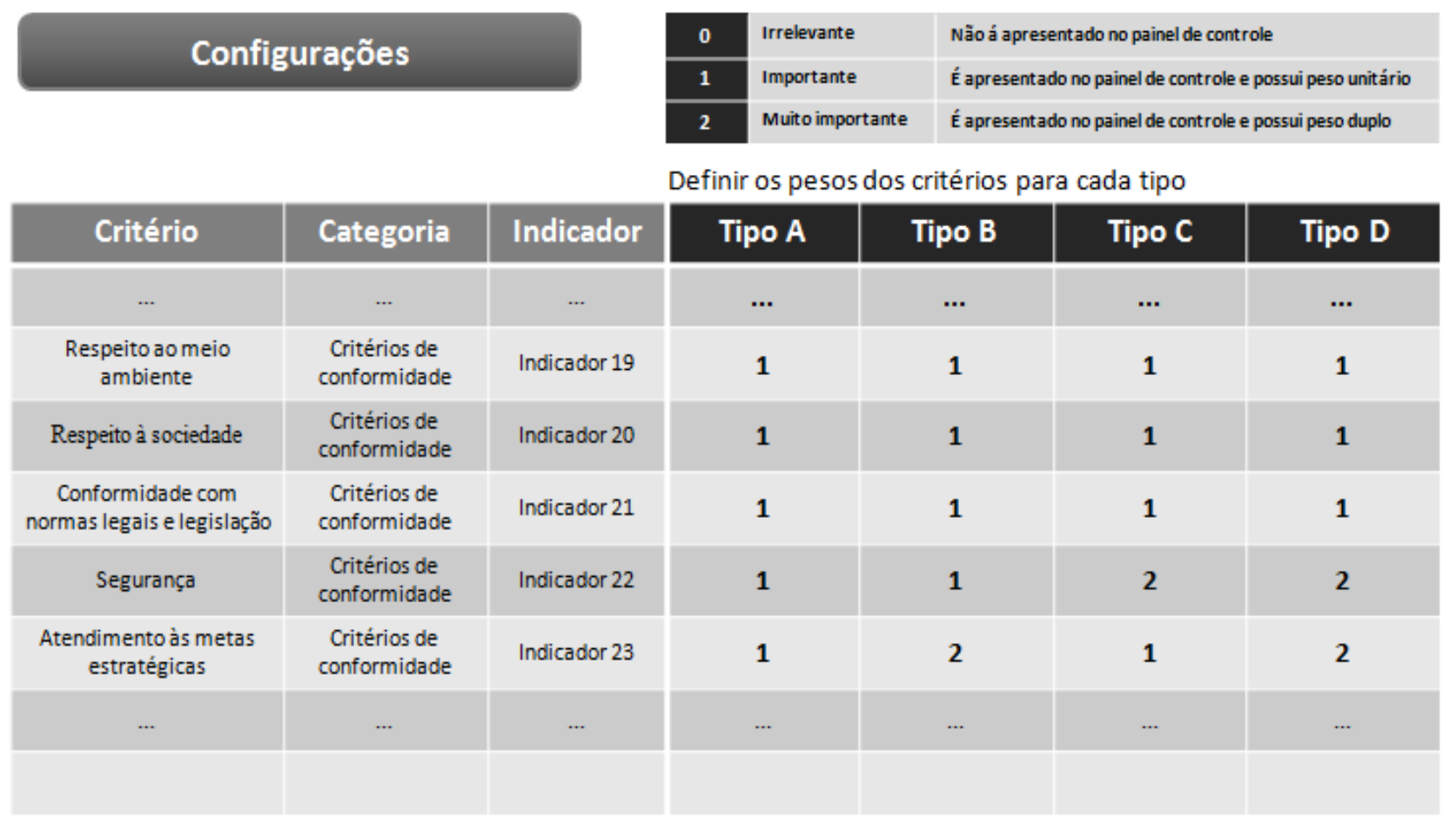

Os pesos foram definidos da seguinte forma:

- os critérios com destacada importância segundo os profissionais consultados "cumprimento de requisitos" e "cumprimento de orçamento" (os critérios "cumprimento de cronograma", "qualidade do serviço" e "clareza na comunicação" foram abordados de maneira individualizada e destacada) receberam peso 2 para todos tipos de projeto;

- os critérios cujo nível de importância se destacou significativamente para determinada tipologia receberam peso 2 ;

- os demais critérios receberam peso 1.

Como nenhum critério em nenhum tipo de projeto foi avaliado como irrelevante, não lhe foi atribuído peso zero, assim, de acordo com as configurações, nenhum deles foi apresentado no painel de controle, somente aqueles com pesos 1 e 2 (Figura 8).

Com base na configuração anterior, gera-se uma máscara com a consolidação do nível de importância de cada critério de sucesso e categoria, para cada tipo de projeto. A Figura 9 apresenta uma máscara exemplo para o projeto do tipo A. 
Figura 9 - Configuração final por tipo de projeto.
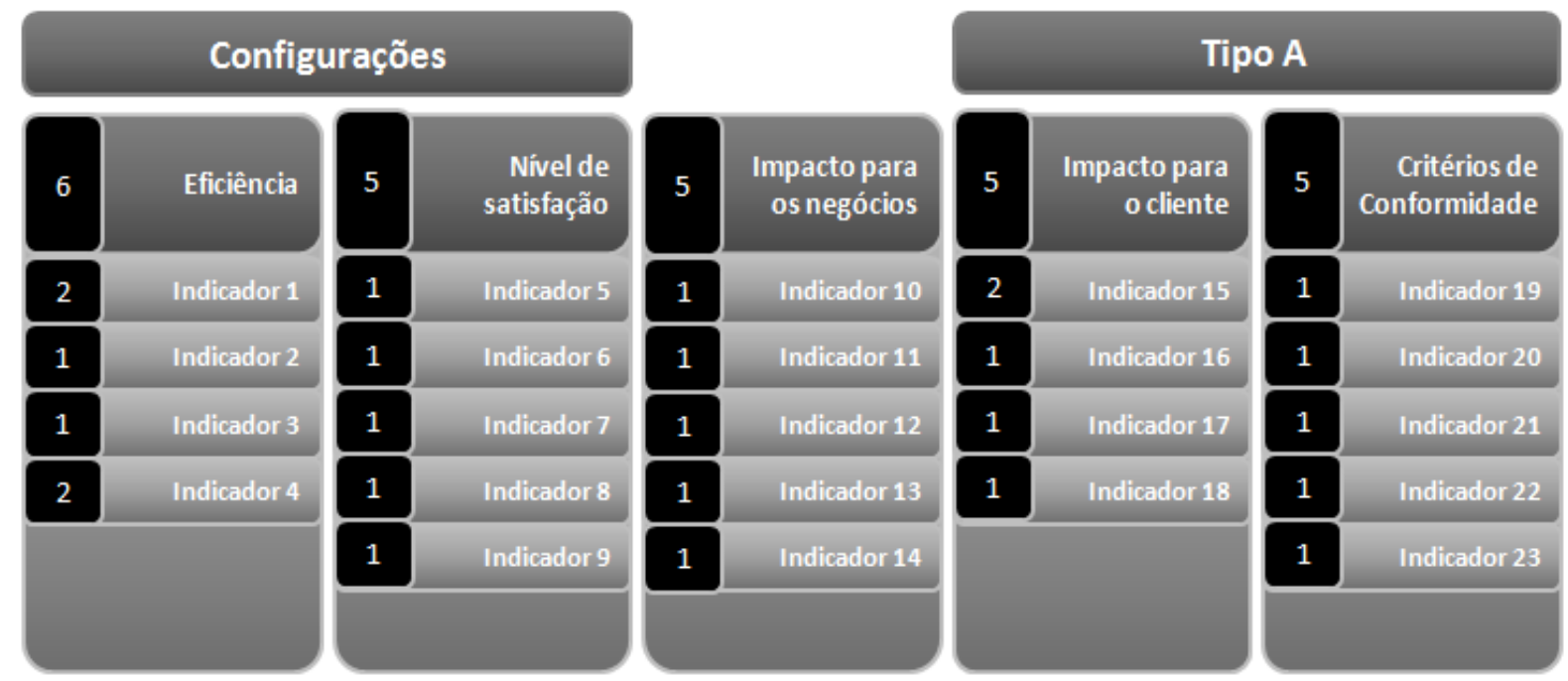

Para a definição do semafórico apresentado na etapa de visualização, faz-se necessária a definição de três zonas de desempenho: cor verde (desempenho satisfatório), amarela (requer atenção), e vermelha (desempenho insatisfatório). A Figura 10 apresenta os critérios para a definição do semafórico das categorias de critérios, os quais devem ser estabelecidos individualmente.

Figura 10 - Critérios para o semafórico da categoria de critérios.

\section{Configurações}

\section{Critérios para o semafórico:}

\begin{tabular}{|c|c|c|c|c|c|c|}
\hline $\begin{array}{l}\text { Categoria } \\
\text { de critérios }\end{array}$ & $\mathrm{Nvd} / \mathrm{N}$ & $\mathrm{Nam} / \mathrm{N}$ & $\mathrm{Num} / \mathrm{N}$ & Observações & $\mathrm{N}$ & $\begin{array}{l}\text { Soma dos pesos dos } \\
\text { indicsdores }\end{array}$ \\
\hline & $100 \%$ & $0 \%$ & $0 \%$ & Todos os indicadores verdes. & Nvd & $\begin{array}{l}\text { Soma dos pesos dos } \\
\text { indicadores verdes }\end{array}$ \\
\hline & $<100 \%$ & $0 \%<\mathrm{Nam} / \mathrm{N}<50 \%$ & $0 \%$ & $\begin{array}{l}\text { Número de indicadores amarelos entre } 1 \mathrm{e} \\
\text { metade dos indicadores e nenhum vermelho. }\end{array}$ & Nam & $\begin{array}{l}\text { Soma dos pesas dos } \\
\text { indicadores amarelas }\end{array}$ \\
\hline & $<100 \%$ & $\begin{array}{l}>=0 \% \\
>50 \%\end{array}$ & $\begin{array}{l}>0 \% \\
>=0 \%\end{array}$ & $\begin{array}{l}\text { Pelo menos } 1 \text { indicador vermelho e/ou mais da } \\
\text { metade dos indicadores amarelos. }\end{array}$ & Nvm & $\begin{array}{l}\text { Soma dos pesos dos } \\
\text { indicadores vermehos }\end{array}$ \\
\hline
\end{tabular}

O número de indicadores de uma determinada categoria de critérios é avaliado da seguinte forma: "r" para status verde, "s" para status amarelo, e "t" para status vermelho. Deve-se considerar os seguintes índices:

Revista de Gestão e Projetos - GeP, São Paulo, v. 2, n. 1, p 174-207, jan./jun. 2011. 
- $\quad \mathbf{N v}-\sum_{i=1}^{r} p_{v} \mathrm{i}$ : soma dos pesos dos indicadores " $\mathrm{r}$ " com status verde $\left(\mathrm{p}_{\mathrm{v}}\right)$;

- Nam - $\sum_{i=1}^{s} p_{a} \mathrm{i}$ : soma dos pesos dos indicadores “s" com status amarelo $\left(\mathrm{p}_{\mathrm{a}}\right)$;

- Nvm - $\sum_{i=1}^{t} p_{v m} \mathrm{i}$ : soma dos pesos dos indicadores " $\mathrm{t}$ " com status vermelho $\left(\mathrm{p}_{\mathrm{vm}}\right)$;

- $\mathbf{N}-\sum_{i=1}^{r} p_{v} i+\sum_{i=1}^{s} p_{a} \mathrm{i}+\sum_{i=1}^{t} p_{v m} \mathrm{i}$ : soma dos pesos de todos os indicadores $(\mathrm{r}+\mathrm{s}+\mathrm{t})$.

Com esses índices, calcula-se a porcentagem dos indicadores em cada um dos status, por meio da razão da soma dos pesos de cada status pela soma de todos os pesos, como apresentado a seguir:

- $\mathbf{R v}$ (porcentagem dos indicadores com status verde) - Nv/N;

- Ra (porcentagem dos indicadores com status amarelo) - Na/N;

- Rvm (porcentagem dos indicadores com status vermelho) - Nvm/N.

Com base nesses cálculos, é definido o status final da categoria de critérios, segundo as seguintes definições (sintetizadas na Figura 10):

- status verde - $R v$ é igual a $100 \%$, todos os indicadores da categoria apresentam status satisfatório;

- status amarelo - $R a$ é maior que zero e menor que $50 \%$ e Rvm é igual a zero, não existem indicadores com status vermelho e a porcentagem de indicadores (considerando seus respectivos pesos) com status amarelo não ultrapassa 50\%;

- status vermelho - $R v m$ é maior que zero ou $R a$ é maior que $50 \%$, existe pelo menos um indicador com status vermelho ou mais da metade dos indicadores com status amarelo.

Para cada indicador definido para mensurar os critérios de sucesso considerados, deve-se estabelecer os seguintes aspectos: nome do indicador, descrição, critério de sucesso mensurado, fonte de dados do indicador, fórmula de cálculo, frequência de atualização e o responsável pela captura dos dados, conforme ilustrado na máscara da Figura 11. Além dos aspectos sugeridos por Crawford e Bryce (2003), foram incluídos os limites inferior e superior para se definir os limites do semafórico do indicador, ou seja, valores inferiores ao limite inferior apresentam status vermelho e valores superiores ao limite superior apresentam status verde; valores entre esses dois limites apresentam status amarelo. Observa-se que essa configuração traz flexibilidade ao sistema, já que permite a inclusão, exclusão ou revisão de indicadores. 
Figura 11 - Detalhamento dos indicadores.

\begin{tabular}{|c|c|c|c|c|c|c|c|c|}
\hline \multicolumn{4}{|c|}{ Configurações } & & & & & \\
\hline Indicador & Descrição & $\begin{array}{l}\text { Critério } \\
\text { de } \\
\text { sucesso }\end{array}$ & Fonte & $\begin{array}{c}\text { Método } \\
\text { ou } \\
\text { fórmula }\end{array}$ & Frequência & $\begin{array}{l}\text { Responsável } \\
\text { pela captura }\end{array}$ & $\begin{array}{l}\text { Limite } \\
\text { inferior }\end{array}$ & $\begin{array}{l}\text { Limite } \\
\text { superior }\end{array}$ \\
\hline Indicador 19 & $x x x$ & $\begin{array}{l}\text { Respeito ao } \\
\text { meio } \\
\text { ambiente }\end{array}$ & $x x x$ & $x x x$ & $x x x$ & $x x x$ & $x x x$ & $\mathbf{x x x}$ \\
\hline & & & & & & & & \\
\hline & & & & & & & & \\
\hline & & & & & & & & \\
\hline & & & & & & & & \\
\hline
\end{tabular}

Uma vez definidas as configurações necessárias, deve-se estabelecer a forma de visualização dos indicadores. Nessa etapa, sugerem-se três máscaras: uma com foco nas necessidades de avaliação do diretor ou do gerente do projeto (Figura 12); uma com foco nas necessidades de acompanhamento do profissional de planejamento financeiro (Figura 13), e uma consolidada com o status de todos os indicadores (Figura 14).

Figura 12 - Máscara de visualização do gerente ou diretor do projeto.

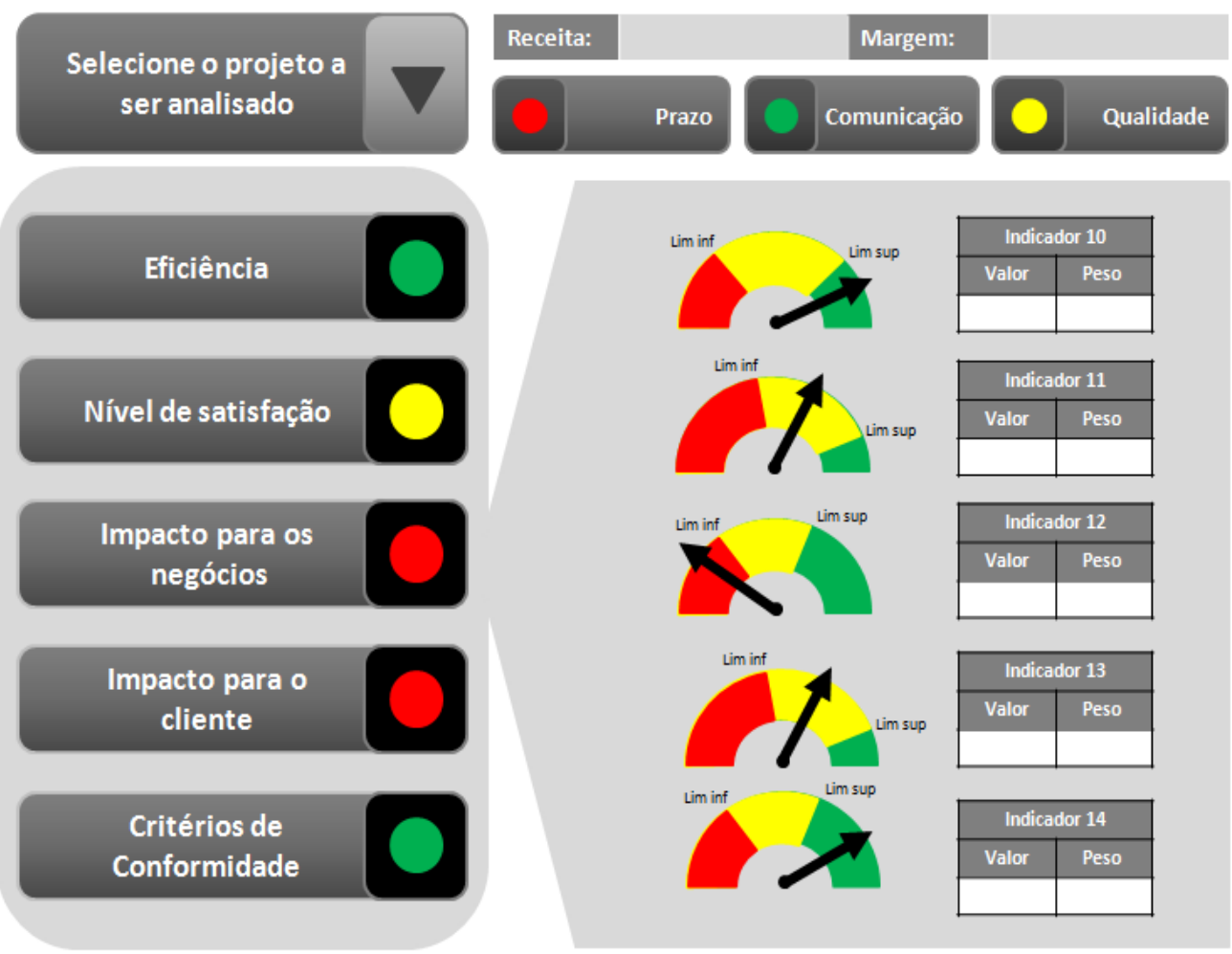

Revista de Gestão e Projetos - GeP, São Paulo, v. 2, n. 1, p 174-207, jan./jun. 2011. 
Figura 13 - Máscara de visualização do profissional de planejamento financeiro.
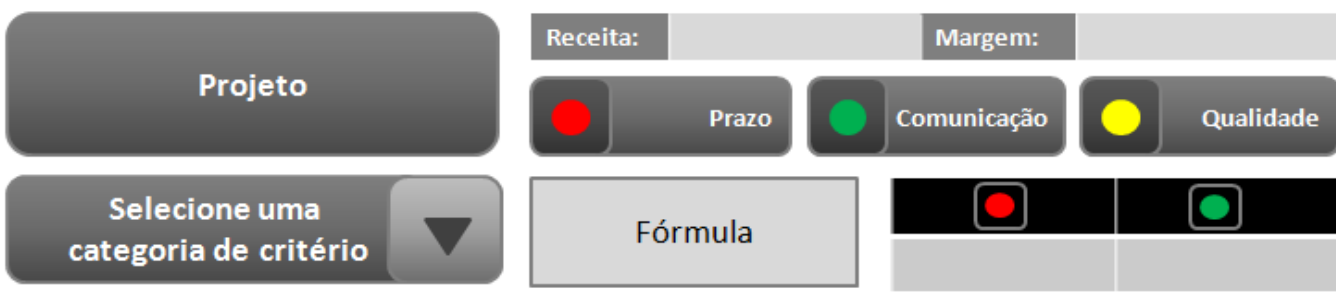

\begin{tabular}{|l|l|}
\hline & Categoria \\
\hline & Indicador \\
\hline & Indicador \\
\hline & Indicador \\
\hline & Indicador \\
\hline & Indicador \\
\hline & Indicador \\
\hline
\end{tabular}

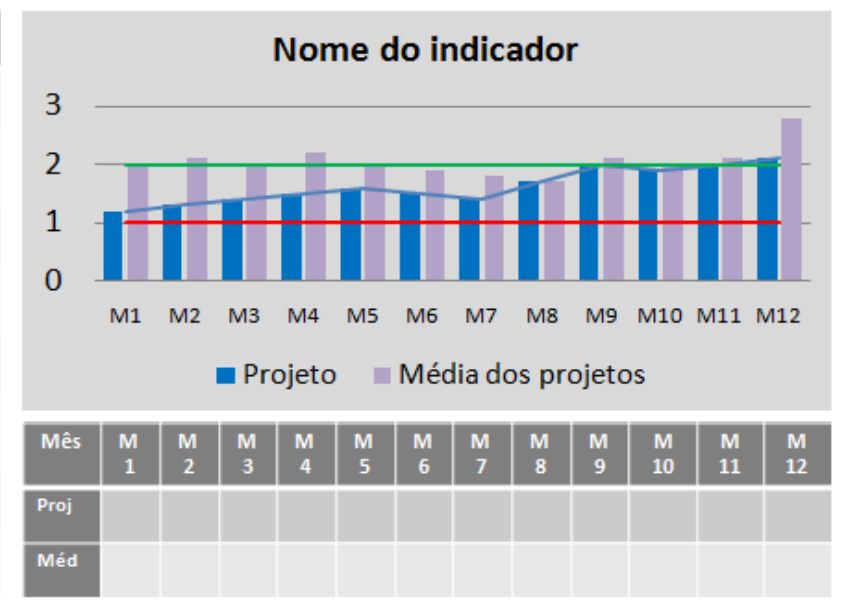

Figura 14 - Visualização consolidada.
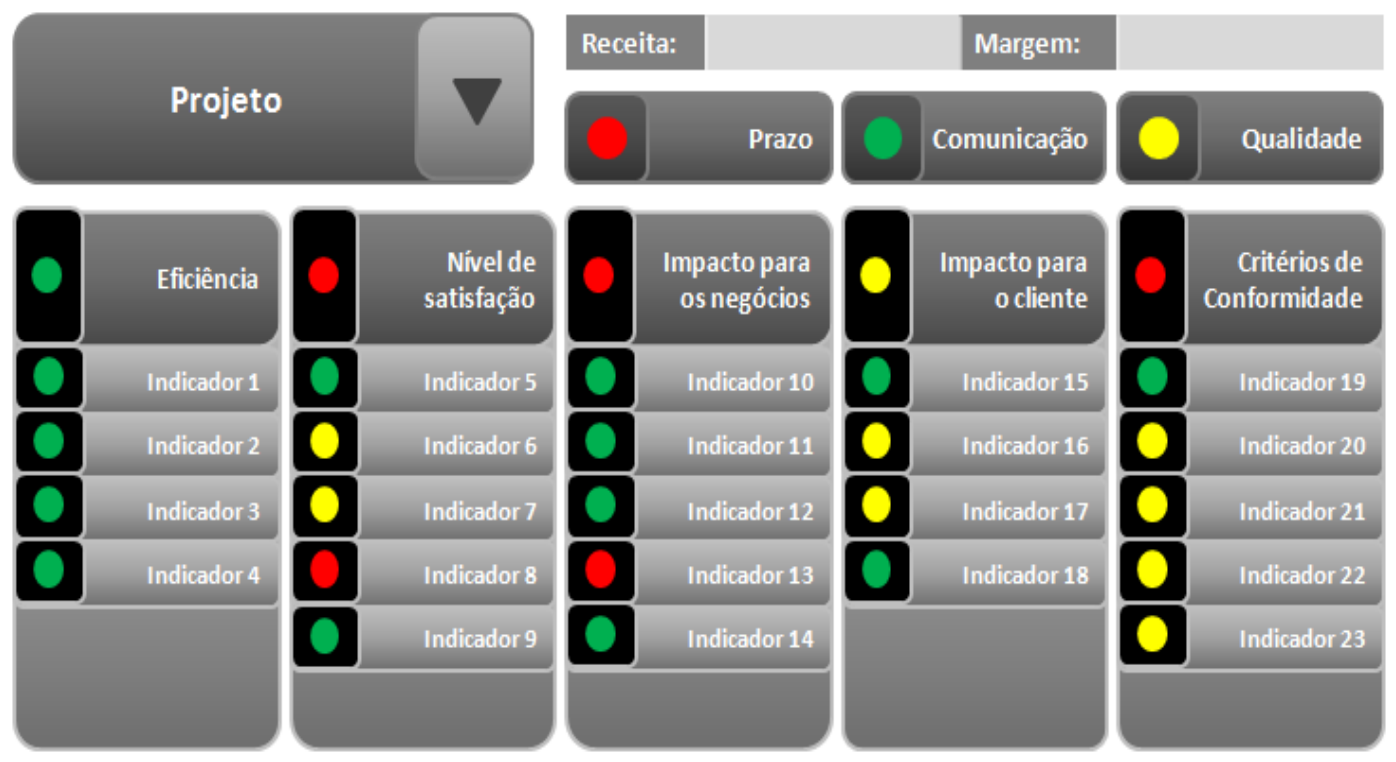

Para a visualização do gerente ou do diretor do projeto, sugere-se uma visão mais consolidada, que consista na apresentação simples e imediata do status dos diversos critérios de sucesso, de modo a permitir seu detalhamento somente quando necessário. Nessa visualização, na caixa de combinação no canto superior esquerdo, o profissional seleciona o projeto que deseja

Revista de Gestão e Projetos - GeP, São Paulo, v. 2, n. 1, p 174-207, jan./jun. 2011. 
analisar e automaticamente são atualizados os valores da receita, a margem do projeto, e o status das categorias de critérios e dos critérios individualizados. Caso o profissional deseje verificar os status dos indicadores que compõem cada categoria, basta selecionar a desejada, que os indicadores, seus respectivos status, valores e pesos serão apresentados.

Para a visualização do profissional de planejamento financeiro, sugere-se uma visão mais detalhada, que permita a apresentação de cada indicador de cada categoria de critério de sucesso de maneira mais completa. Na parte superior são apresentadas informações sobre a receita e a margem do projeto e sobre os critérios de sucesso julgados de maior relevância, prazo, comunicação e qualidade. Na lateral esquerda, deve-se selecionar na caixa de combinação a categoria de critério que se deseja analisar. Uma vez selecionada, os indicadores a ela pertencentes são automaticamente apresentados, juntamente aos seus respectivos status. Para se ver o detalhe de determinado indicador basta selecioná-lo, que as informações à direita são automaticamente atualizadas. Assim, apresenta-se a fórmula de cálculo do indicador selecionado, os critérios para a definição dos status vermelho e verde (de forma gráfica e valor), o histórico do indicador (de forma gráfica e o valor), e o histórico da média do indicador para todos os projetos da organização (de forma gráfica e valor).

Finalmente, para se ter uma visão consolidada de determinado projeto, sugere-se uma máscara a ser consultada tanto pelo gerente ou diretor do projeto quanto pelo profissional de planejamento financeiro. Essa máscara apresenta o status de todos os indicadores de um determinado projeto em uma única visão. Assim, caso se deseje verificar detalhes sobre determinado indicador, ao selecioná-lo, o aplicativo será direcionado para a visão detalhada e completa do profissional de planejamento financeiro.

De maneira geral, observa-se que o sistema de indicadores proposto contempla todos os aspectos inicialmente mencionados e considera: as perspectivas dos principais stakeholders; a diferença no nível de importância dos critérios de sucesso para cada tipo de projeto que é flexível no que concerne a revisão dos indicadores nele presentes; e a temporalidade na apresentação dos indicadores com sua atualização automática.

Revista de Gestão e Projetos - GeP, São Paulo, v. 2, n. 1, p 174-207, jan./jun. 2011. 


\section{CONSIDERAÇÕES FINAIS}

O presente trabalho visou a proposição de um sistema de indicadores de desempenho considerando a teoria contingencial de projetos referente aos seus critérios de sucesso (Shenhar, 2001). Os resultados da pesquisa de campo e a análise de dados no âmbito da organização estudada permitiram a constatação de que a tipologia dos projetos influencia no nível de importância dos fatores críticos de sucesso, porém, o mesmo não ocorre para os diferentes stakeholders analisados. Por meio da elaboração de uma análise fatorial a partir dos dados coletados na pesquisa de campo pode-se definir as categorias de critérios de sucesso, de acordo com aquelas sugeridas na literatura, tomando-se como ponto de partida o modelo proposto por Shenhar e Dvir (2007). Finalmente, fezse uma análise do atual sistema de indicadores da empresa, visando diagnosticar sua situação atual com relação aos indicadores de desempenho de projetos. Com base nessas evidências e análises, o sistema de indicadores proposto visou contemplar a diferença do nível de importância dos critérios para cada tipo de projeto e tratar as limitações da ferramenta atualmente utilizada na organização. Aproveitou-se a implantação piloto de uma nova plataforma de sistemas de indicadores para subsidiar a proposição do novo sistema.

É importante ressaltar que as etapas descritas e seguidas no presente trabalho podem ser facilmente replicadas em qualquer organização. Os métodos utilizados, uma vez compreendidos, são de fácil aplicação e as ferramentas empregadas, como o Minitab (Statistical Software) e o SPSS (Statistical Package for the Social Sciences), apresentam versões gratuitas disponíveis na web. O fato de o método ser replicável não implica que os resultados sejam generalizáveis. Por exemplo, as perspectivas dos stakeholders podem mudar ou mesmo novos stakeholders podem vir a ser considerados.

Apesar de alguns pesquisadores já terem desenvolvido trabalhos relacionados ao levantamento de métricas para o acompanhamento do negócio da empresa (Kaplan e Norton, 1996; Neely et al., 2001), pesquisas em torno de métricas para projetos são recentes (Crawford e Bryce, 2003; Barclay e Osei-Bryson, 2010), de maneira que esse tema não dispõe de investigações amplas (Kezner, 2011). Dessa forma, o presente trabalho contribui para o fomento de estudos que promovam o enriquecimento do conteúdo desenvolvido nessa área.

Revista de Gestão e Projetos - GeP, São Paulo, v. 2, n. 1, p 174-207, jan./jun. 2011. 


\section{REFERÊNCIAS}

Barclay, C. and Osei-Bryson, K. M. (2010). Project performance development framework: an approach for developing performance criteria \& measures for information systems (IS) projects. International Journal of Production Economics, 124(1), 272-292.

http://dx.doi.org/10.1016/j.ijpe.2009.11.025

Cheung, S.; Suen, H.; and Cheung, K. (2004). PPMS: a web-based construction project performance monitoring system. Automation in Construction, 13(3), 361-376.

http://dx.doi.org/10.1016/j.autcon.2003.12.001

Crawford, P. and Bryce, P. (2003). Project monitoring and evaluation: a method for enhancing the efficiency and effectiveness of aid project implementation. International Journal of Project Management, 21(5), 363-373. http://dx.doi.org/10.1016/S0263-7863(02)00060-1

Construction Industry Institute. (2006, October). Research Summary 220-1: Leading indicators during project execution. eNews. Austin, TX, USA: The University of Texas.

Freeman, R. (1984). Strategic management: a stakeholder approach. Boston: Pitman.

Kaplan, R.; Norton, D. The balanced scorecard: translating strategy into action. Harvard Business Press, 1996.

Kennerley, M. and Neely, A. (2002). A framework of the factors affecting the evolution of performance measurement systems. International Journal of Operations and Production Management, 22(11), 1222-1245.

http://dx.doi.org/10.1108/01443570210450293

Kezner, H. (2006). Project management best practices: achieving global excellence. Hoboken, NJ, USA: John Wiley \& Sons Inc.

Kerzner, H. Project Management Metrics, KPIs, and Dashboards: A Guide to Measuring and Monitoring Project Performance. International Institute for Learning, Inc., New York, NY, 2011, $374 \mathrm{p}$.

Neely, A. (2005). The evolution of performance measurement research. International Journal of Operations \& Production Management, 25(12), 1264-1277.

http://dx.doi.org/10.1108/01443570510633648

Neely, A.; Adams, C.; and Crowe, P. (2001). The performance prism in practice. Measuring Business Excellence, 5(2), 6-12. http://dx.doi.org/10.1108/13683040110385142

Revista de Gestão e Projetos - GeP, São Paulo, v. 2, n. 1, p 174-207, jan./jun. 2011. 
Pillai, A.; Rao, K. Performance monitoring in R\&D projects. R\&D Management, v. 26, n. 1, p. 57 65, 1996.

Pillai, A.; Joshi, A.; and Rao, K. (2002). Performance measurement of R\&D projects in a multiproject, concurrent engineering environment. International Journal of Project Management, 20( 2), 165-177. http://dx.doi.org/10.1016/S0263-7863(00)00056-9

Project Management Institute. (2003). Organizational project management maturity model (OPM3): knowledge foundation. Newtown Square, PA, USA: Project Management Institute.

Project Management Institute. (2008). Um guia do conhecimento em gerenciamento de projetos (PMBOK). Newtown Square, PA, USA: Project Management Institute.

Shenhar, A. J. (2001). One size does not fit all projects: exploring classical contingency domains. Management Science, 47(3), 394-414.

http://dx.doi.org/10.1287/mnsc.47.3.394.9772

Shenhar, A. and Dvir, D. (2007). Reinventing project management: the diamond approach to successful growth and innovation. Boston: Harvard Business School Press.

Data do recebimento do artigo: 18/04/2011

Data do aceite de publicação: 11/06/2011

Revista de Gestão e Projetos - GeP, São Paulo, v. 2, n. 1, p 174-207, jan./jun. 2011. 